\title{
Why We Are Not Acting to Save Ourselves: ACT, Health, and Culture
}

\author{
Ruth Anne Rehfeldt ${ }^{1}$ (D) $\cdot$ Ian Tyndall ${ }^{2}$ (D)
}

Accepted: 3 April 2021 / Published online: 15 July 2021

(C) Association for Behavior Analysis International 2021

\begin{abstract}
Chronic health conditions are increasing at an alarming rate worldwide, and many could be prevented if people were to engage in specific lifestyle behaviors. Intervening on lifestyle behaviors is challenging due to the fact that the consequences associated with unhealthy behaviors are temporally distant and probabilistic, and the aversive functions of covert stimuli may interfere with people's engagement in healthy, preventative behaviors. This article explores the role of relational framing in the promotion of healthy lifestyle behaviors and summarizes research supporting the use of acceptance and commitment training (ACT) as a framework for prevention and intervention. We explore how ACT alters the context in which rigid patterns of rule following occur. ACT loosens the literal functions of stimuli so that experiential-avoidance behaviors are weakened, and healthy, valuesconsistent behaviors are strengthened. We propose culture-wide interventions inspired by contextual behavior science so that healthier societies can be cultivated.
\end{abstract}

Keywords health $\cdot$ prevention $\cdot$ relational frame theory $\cdot \mathrm{ACT} \cdot$ culture

Chronic health conditions create suffering. They compromise an individual's ability to live a life characterized by wellness and vitality. Many health conditions are preventable. A number of lifestyle behaviors are considered key in prevention, as are screening and early detection. Research in behavioral medicine suggests that engaging in lifestyle behaviors such as engaging in physical activity, abstaining from smoking, eating healthily, and drinking low volumes of alcohol or abstaining entirely might prevent the development of chronic disease (Hagger et al., 2020). Despite this body of knowledge, the rates of chronic health problems are increasing. Why this might be the case, when there is substantial literature on behavioral interventions for reducing unhealthy behaviors and increasing healthy behaviors, needs to be examined with a critical lens.

There are encouraging signs of recognition that, although the literature on behavioral interventions from the fields of

Authorship is equal and listed alphabetically.

Ruth Anne Rehfeldt

rrehfeldt@ thechicagoschool.edu

1 The Chicago School of Professional Psychology, Chicago, 325 N. Wells St, Chicago, IL 60654, USA

2 Department of Psychology, University of Chichester, Chichester, West Sussex, UK health psychology and public health is sizable, what is needed is a coherent science of behavior change (Hagger et al., 2020). As Zhang et al. (2018) highlighted, the sheer extent of the negative impact of health problems on well-being (whether social, emotional, economic, or physical) suggests that a reanalysis of approaches to fostering cultural change in the context of health behavior is warranted. It might seem, therefore, that the suffering created by some chronic health conditions is avoidable and unnecessary. We feel that behavior analysis as a field is ideally positioned as a coherent science of behavior to provide leadership to promote a healthier society.

A challenge in developing effective interventions is the fact that the consequences for lifestyle behaviors are both temporally distant and probabilistic, a reality alluded to by Skinner (1987) in his seminal paper "Why We Are Not Acting to Save the World." Skinner (1987) stated that

the more remote the predicted consequences, the less likely we are to follow advice. We have more often been successful when we have followed advice about the immediate future because that kind of advice has been more often tested and found better. The advice we are now being offered is about a distant future; it may be good advice, but that has very little to do with whether we shall take it. (p. 5) 
In support of Skinner's (1987) point, many health conditions develop after years of ongoing patterns of behavior, and it is not absolutely certain that a person who engages in unhealthy behavior will experience health issues later in life. The threat of a far-removed aversive consequence may thus be insufficient to influence everyday decision making regarding one's health.

Specialized antecedent and consequent interventions have been designed to facilitate the adoption of healthy lifestyle practices for this reason. Such interventions are based on the effects of direct-acting contingencies and show promise for increasing healthy lifestyle behaviors (see Normand \& Bober, 2020). Skinner (1987) anticipated the success of such interventions by asking,

Why not arrange immediate consequences that will have the effect that remote consequences would have if they were acting now? There is nothing very new in that suggestion. . . . Cultures have helped to solve the problem by supplying immediate consequences that have the same effect as the remote ones. (p. 6)

The psychological experience surrounding health-both for those hoping to prevent the development of a chronic condition and for those enduring one - should also be considered. Anxiety and depression have been shown to occur at a high prevalence in people living with chronic health conditions (Farrand \& Woodford, 2015), and for many people, even thinking about the possibility of a serious illness arouses fear (Dunn et al., 1993). In the face of a distressing psychological experience, the natural tendency is for people to avoid the stimuli that elicit such reactions: An individual deliberating whether or not they should eat a fast-food meal may tell themselves, 'I don't need to think about it now; I'll worry about it when I get older," and consume the meal. An individual experiencing worrisome health symptoms might avoid seeking medical attention to avoid receiving frightening news. Such avoidance strategies have deleterious effects in the long run and are verbally mediated.

The purpose of this article is to explore, from a contextual behavior science perspective, the processes involved in health-related behaviors. The contextual behavior science stance is an elaborated behavior-analytic approach that involves exploring the role of context in influencing behavior at the individual, community, and cultural levels (Vilardaga et al., 2009). The "world within the skin" is thus viewed as much a part of that context that influences behavior as external environmental contingencies (Hayes et al., 2017): People interact with covert rules and expend efforts to avoid uncomfortable psychological experiences (i.e., private events). We begin by discussing the prevalence of chronic health conditions in the general population and their linkage to specific lifestyle behaviors, followed by an analysis of some obstacles to promoting behavior change. We then explore how relational framing may promote rigid patterns of rule following that are incongruous with values-consistent, healthy lifestyle behaviors, and summarize research in support of the efficacy of acceptance and commitment training (ACT; Hayes et al., 2004) in fostering healthy repertoires. We conclude with a discussion of potential cultural-level interventions within and beyond health care inspired by contextual behavior science. Throughout this article, we adopt the word "training" in lieu of "therapy" in the ACT acronym (see Blackledge \& Hayes, 2006; Hayes et al., 2004) to underscore the conceptualization of ACT as a framework for expanding adaptive repertoires in all people, as opposed to a treatment for psychological disorders only (Levin et al., 2016).

\section{Chronic Health Conditions: Burdensome and Preventable}

The medical community defines chronic health conditions as conditions that last 1 year or more, require ongoing medical attention, and limit the activities of daily living (Centers for Disease Control and Prevention, 2021). The most common chronic conditions include heart disease, stroke, cancer, and diabetes, which together are estimated to be responsible for more deaths worldwide than infectious diseases. The World Health Organization (WHO) predicts that chronic diseases will account for almost three quarters of all deaths worldwide this year (WHO, 2021a). Obesity and diabetes are occurring at younger and younger ages. According to WHO (2021b), approximately 422,000,000 adults live with diabetes mellitus worldwide. Treating chronic diseases, particularly at such a high prevalence, creates an economic burden for society. Chronic diseases contributed approximately $46 \%$ to global health care costs in 2001; the proportion of the burden is expected to increase to $57 \%$ by 2020 (WHO, 2021a).

Most chronic health conditions have been linked to specific behaviors, suggesting that if people changed their behaviors, certain conditions could be preventable. Ongoing tobacco use, poor nutrition, excessive alcohol use, and a sedentary lifestyle are all strong determinants of whether or not a person will develop a chronic health condition. To wit, WHO estimates that $80 \%$ of cardiovascular disease, including heart attacks and strokes, could be prevented if people stopped using tobacco, ate a healthier diet, and exercised regularly, and $40 \%$ of cancer cases could similarly be prevented (Saphier, 2020). Although a number of health conditions appear to have a probable genetic basis, epidemiological studies have questioned whether genetics can be considered a primary cause in many cases (see Rappaport, 2016). Today's evolutionary science perspective acknowledges that an individual's interaction with their own sociocultural community is as important of an influence on behavior as genetic susceptibility (Wilson, 2014). 


\section{Some Obstacles}

The onset of a chronic health condition would seem on the surface to be an aversive consequence following years of engagement in unhealthy behaviors. Chronic health conditions have painful and often debilitating symptoms, and many treatments have unpleasant side effects. However, considerable research has shown that delayed outcomes are less successful at influencing behavior than more immediate outcomes (Critchfield \& Kollins, 2001), and the contingency between lifestyle behaviors and health conditions is highly probabilistic. As Skinner (1987) described, "We are being asked to do something about the future. But the future does not exist. It cannot act upon us; we cannot act upon it" (p. 2). Behavioral interventions to date have thus focused on the implementation of relatively short-term direct-acting contingencies, including antecedent and consequent manipulations such as prompts, instructions, and environmental modifications to set the occasion for healthy behaviors, and praise, monetary reinforcement, and tangible goods to reinforce such behaviors (Normand et al., 2015). Specialized functional assessment methodologies have been designed to identify the conditions under which healthy behaviors are likely to occur (see Hustyi et al., 2012). Such interventions have been shown to be generally effective and found acceptable by participants (Green \& Dallery, 2019). Educational programs such as Food Dudes (Tapper et al., 2003), a curriculum that was designed to increase school-age children's choices for healthy food items, also show promise, but its long-term efficacy is currently unknown (Upton et al., 2013).

Covert stimulation may also influence an individual's engagement in prevention-related behaviors. Critchfield and Reed (2016) suggested that people's private psychological experience can actually interfere with such behaviors. These authors taught undergraduate participants to discriminate between melanoma and nonmelanoma images, and found that discriminations were disrupted when participants were given verbal information about the risks and mortality rates of skin cancer. The authors speculated that the information on skin cancer elicited adverse psychological reactions in participants, as participants were likely thinking about the information as they completed the discrimination task. Their findings may well parallel the experience of people engaging in screening and prevention-related behaviors outside of the laboratory, where patient-education efforts rely on verbal information about risks and warning signs. For many, reading and thinking about disease may be so aversive that they avoid engaging in behaviors where such an unpleasant psychological experience is likely to occur. Public health studies have shown that people may delay seeking medical treatment - in some cases indefinitely - to avoid interacting with unpleasant private stimuli (Donovan et al., 2003). The United States, for example, has one of the most robust breast cancer screening programs in the world, but 50\% of American women report not getting mammograms because they are "afraid of the results" (Saphier, 2020).

Thus far we have examined two obstacles in the design of interventions to promote healthy lifestyle behaviors, including the fact that temporally remote and probabilistic contingencies may be ineffective at influencing behavior, and the fact that thinking about one's health may be aversive or frightening in its own right, leading people to avoid contexts in which such problematic thoughts are likely. We now examine the additional challenges and solutions presented by relational frame theory (Hayes et al., 2001) and its conceptualization of the relational basis of human behavior.

\section{Relational Frame Theory: How Language "Cuts Both Ways"}

In the context of understanding preventative measures and informing therapeutic interventions in health behavior, relational frame theory (RFT) offers scope and breadth (Zhang et al., 2018). RFT focuses on the function-altering effects of language (Forsyth \& Eifert, 1996) in terms of how rules and other verbal stimuli come to exert control over behavior. For example, abiding by the rule that "one cigarette won't do any harm" on a daily basis over many years might lead to insensitivity to health-related contingencies, such as premature development of breathlessness walking up a flight of stairs or early aging of the skin. In a sense, it might be conceptualized that an equivalence relation has been derived between "one cigarette" and "no harm" or "safe." Similarly, a person might have derived an equivalence relation between "smoking" and "pleasure" or "cigarette" and "relaxing," and those verbal rules come to exert stronger functional control over behavior than a rule such as "smoking causes heart disease/cancer." It could also be the case that the person who smokes is engaging in avoidance of private events, where any thoughts about the future development of chronic obstructive pulmonary disease or lung cancer are simply ignored.

According to RFT, patterns of derived relational responding (e.g., relational frames such as sameness/coordination, opposition, distinction, more than / less than, temporal [now/then]), or responding to one event in terms of another in accordance with the contingencies of one's sociocultural context (Critchfield \& Rehfeldt, 2019), are the key generalized operants underlying language and cognition (Dymond \& Roche, 2013). A fundamental property of relational framing is the transformation of stimulus functions (Dymond \& Rehfeldt, 2000; Dymond et al., 2007), which specifies that the functions of stimuli involved in relational networks change in accordance with the relational networks in which they participate. The transformation-of-functions phenomenon is observed when the behavioral functions of stimuli transfer via a 
relational network (e.g., a three-member stimulus equivalence class: A-B-C) to other stimuli that previously did not influence that behavior (e.g., Dougher et al., 1994).

As Dymond and Rehfeldt (2000) described, if one of the stimuli in a relational network is established as a discriminative stimulus for a given response, then other members of the network will typically acquire discriminative properties without further training. This process could help account for derived avoidance of a yet-to-be-experienced event rather than directly conditioned avoidance. Derived avoidance of medical procedures not yet experienced could potentially lead to negative health consequences such as allowing an aortic aneurism "bulge" in an artery wall or a tumor to develop and spread undetected. For example, if a person is already slightly anxious about Stimulus A (medical check procedure A), which they have previously experienced, and is told that A is less painful than Stimulus B (medical procedure B) and B is less painful than Stimulus $\mathrm{C}$ (medical procedure $\mathrm{C}$ ), an individual who has otherwise never encountered medical procedure $\mathrm{C}$ might display symptoms of extreme avoidance when offered it and not travel to the clinic or hospital on an appointed date.

The transformation-of-functions effect extends a person's behavioral repertoire in the absence of direct training or reinforcement (Tyndall et al., 2009). However, a flip side to the generally adaptive transformation-of-function effect, as Dymond et al. (2018) argued, is that this very relational basis of human behavior leads to both suffering and self-destruction. To illustrate, the stimulus function of an aversive event, such as dysregulated breathing, can be transferred to a neutral event. Consider a recreational hike with friends. For some, just thinking about or planning the hike can lead to dysregulated breathing. If the person experiencing this discomfort withdraws from the event, they will lose out on potentially important opportunities for social reinforcement.

In a classic laboratory analog study, Augustson and Dougher (1997) trained eight participants in the formation of two four-member equivalence classes. They subsequently established an avoidance response (CS+) - pressing the space bar on a computer keyboard 20 times prior to the potential administration of a mild electric shock - for a discriminative stimulus (B1) that was also a member of one of the equivalence classes (A1-B1-C1-D1). The avoidance response was shown to transfer to the other members of the particular equivalence class and not to members of the other equivalence class (A2-B2-C2-D2). Guinther and Dougher (2015) proposed that such an observed transfer of function across stimulus equivalence classes could provide a behavioral account of the etiologies of avoidance responses that appear to have emerged in the absence of any explicit history of reinforcement for avoidance in the natural environment.

Dymond et al. (2008) established an equivalence (or coordination) relation with a pair of nonsense word stimuli and an "opposite" set (i.e., pair) of stimuli through direct training. In the absence of feedback, participants subsequently derived equivalence relations within both pairs and, importantly, derived opposite relations between both pairs. Using a fearconditioning paradigm, a stimulus from the equivalence set was aversively conditioned, in that pressing the space bar on a keyboard functioned to control avoidance of the aversive stimulus. A nonaversive conditioning procedure was employed for one stimulus from the opposite set (i.e., a space-bar-press response was withheld). Broadly speaking, generalized avoidance was observed as participants subsequently produced a higher rate of avoidance (i.e., pressing the space bar) in the presence of the other stimulus of the equivalence set (i.e., the non-directly conditioned stimulus) than the remaining stimulus of the opposite pair. To summarize, a derived equivalence relation, where one member of the equivalent set was a directly aversively conditioned stimulus, seemed to function as a context for generalized (or symbolic) avoidance behavior, whereas derived opposition relations did not.

What are the implications, then, of such basic empirical studies on verbal and symbolic behavior from the laboratory with respect to health? As Hayes, Strosahl, and Wilson (2012) argued, it is via normal language processes that much human suffering emerges. From an RFT perspective, an unfortunate counterproductive consequence of arbitrarily applicable relational responding is a tendency to engage in symbolically derived maladaptive avoidance behavior (Dymond et al., 2018). A behavioral practitioner working within an RFT framework would aim to either strengthen or weaken relational frames that are already apparent in a client's verbal behavior repertoire, and to also set the occasion for learning novel and more adaptive relational responses in the context of specific health-behavior targets (Zhang et al., 2018).

As outlined previously, RFT proposes that verbal relations (e.g., verbal rules) are learned through direct and derived processes (e.g., Dymond et al., 2008). Thus, a key implication is that it is not fully possible to remove the historically established psychological relations between environmental cues and past unhealthy behaviors. Many typical cognitive therapy approaches focus on changing or removing the content of a person's cognitions via techniques such as thought stopping or cognitive restructuring. From an RFT stance, however, such strategies are likely to be unproductive in facilitating long-lasting behavior change because, as Forsyth and Eifert (1996) noted, there is no psychological process called unlearning. Thus, RFT suggests that a more fruitful approach would be to focus on altering the context in which the verbal rules are evoked in order to strengthen or weaken the behavioral impact of rules rather than try to eliminate or change the rules themselves.

At this juncture, it is important to accede that, to date, very little empirical work has been conducted within an RFT framework with respect to public health. The current treatise is speculative and serves somewhat as a call to arms to encourage 
basic and applied investigations to develop the fresh perspective needed to promote lasting health-behavior change.

ACT has particular potential to serve as one key fresh approach to health-behavior change due to its coherent theoretical framework (Hayes, Pistorello, \& Levin, 2012), transdiagnostic scope (Levin et al., 2014), and adaptability across a variety of health and cultural contexts (Zhang et al., 2018; Hayes, Barnes-Holmes, \& Wilson, 2012). The emphasis within ACT and RFT on altering the context in which verbal rules are experienced or acted upon is key to a psychologically flexible approach to health (Guinther \& Dougher, 2015; Kashdan \& Rottenberg, 2010; Zhang et al., 2018). Psychological flexibility is conceptualized as a person's awareness of the stimuli included in the present moment, including one's psychological experience, while engaging in values-consistent behaviors that achieve important external reinforcers. With ACT, a wide array of behavioral techniques is employed to encourage clients to experience stimulus events with psychological distance, or mindful awareness (Levin et al., 2020). This allows for greater variability in response functions in the presence of such stimuli, rather than automatically following the conditioned response functions of the stimuli per se. An ACT practitioner might endeavor to establish contexts in which relational-framing behavior might emerge (e.g., Hayes, 2004) that could support desirable and adaptive behavioral change (e.g., establish a frame of equivalence or coordination between engaging in a difficult healthbehavior task and a person's chosen values). ACT practitioners rely heavily on the use of analogy and metaphor to evoke psychological distance between a person's covert (e.g., thoughts) and overt responses. This sets the stage for identifying a client's values and the behaviors that would commit them to those values.

There is mounting evidence for the efficacy of ACT interventions across many health-behavior domains (e.g., A-Tjak et al., 2015; Manchón et al., 2020), including reducing cigarette smoking (e.g., Bricker et al., 2014; Bricker et al., 2013), increasing physical activity (Manchón et al., 2020; Moffit \& Mohr, 2015), and losing weight (Forman \& Butryn, 2015). Indeed, Gloster et al. (2017) proposed that increasing psychological flexibility among the general population could be a public health target that is potentially achievable.

It is important to note that, from an ACT perspective, there is no one correct way to implement ACT, and there are a great variety of ways to conduct ACT-based work with many diverse methods. In other words, rather than rigidly adhering to a particular technique or specific protocol, a practitioner focuses on the "act in context" and pragmatic workability in order to broaden a client's behavioral repertoire in line with self-chosen values. An ACT trainer or coach in a health context would help a client become more aware of their thoughts or self-stories (e.g., "Well, I'm already overweight, so what's the point in cutting down on food?" or "I'll never be fit again") in terms of thinking as a dynamic, ongoing relational process, rather than the thought as a fixed or static product. From the workability perspective, the ACT health coach focuses their intervention on what they can predict and influence in terms of a client's behavior. Indeed, this can be very different across clients in one-to-one sessions or support-group formats (e.g., weight-loss groups), even though on the surface the behavioral or health problem might look quite similar across that client group (e.g., smokers, obese persons, excessive drinkers).

The following section will detail three (experiential avoidance, cognitive fusion, and lack of values clarity) of the six core processes (others being self-as-content, lack of present moment awareness, and noncommittal to action) of psychological inflexibility (i.e., the polar opposite of psychological flexibility; Hayes et al., 2006) that are most relevant to consider in the context of health. Cognitive fusion and experiential avoidance are particularly central processes and are often viewed as a pair working together to facilitate maladaptive patterns of behavior (e.g., Bardeen \& Fergus, 2016). In simple terms, cognitive fusion refers to responding to the content of one's thoughts as if they are literally true, whereas experiential avoidance relates to attempts to control or regulate thoughts, feelings, and emotions (Dixon \& Paliliunas, 2020). From a functional-analytic perspective, mindfulness-based interventions typically encourage people to discriminate between private events and stimuli occurring in the person's social and physical environment, as well as attend to situations in which their private verbal behavior is not functionally adaptive. An ACT practitioner would ascertain the function of private (i.e., verbal) and publicly observable behavior and employ behavioral strategies to reduce rigid and excessive rule-following behaviors that are not adaptive for living a healthier life (see Dixon \& Paliliunas, 2020; Fletcher \& Hayes, 2005).

\section{Experiential Avoidance}

Experiential avoidance is a cardinal component of the psychological inflexibility model that appears to be closely tied to the development of negative health outcomes (Hayes et al., 1996; Karademas et al., 2017). With respect to health, experiential avoidance likely involves the avoidance of internal private events (e.g., thoughts about developing cancer or feelings of breathlessness due to obesity). For example, not engaging in physical activity could serve the function of avoiding internal experiences (Manchón et al., 2020) such as thoughts, sensations, or emotions related to the physical exercise (e.g., fearing the painful muscle aches that might emerge following a session on the treadmill or lifting weights at a gym). Avoiding medical consultation may serve a similar function. Experiential-avoidance behaviors are negatively reinforced as they remove the private event associated with an aversive stimulus (e.g., anxiety-evoking thought about mortality), rather than the aversive stimulus itself. 
A negative impact of experiential avoidance on physical health might emerge if a person engages in unhealthy behavioral responses such as binge eating (see Lillis et al., 2011), consuming alcohol excessively, or chain-smoking while experiencing stress. These maladaptive behavioral responses might provide initial relief and comfort, as they help suppress or avoid unwanted aversive private events (e.g., thoughts and memories about a stressful day at work). However, over the long term, if this behavioral response pattern becomes rigid and deeply embedded as a go-to experiential-avoidance response to everyday stressors, it can have severe detrimental health consequences over time.

\section{Cognitive Fusion}

Cognitive fusion appears to have direct links to physical health (Bodenlos et al., 2020; Trindade et al., 2020; Trindade et al., 2018). Cognitive fusion refers to a contextually controlled behavior-behavior relation in which private events (i.e., thoughts and feelings) are responded to as if they are literally true, rather than just as simply more stimuli in a person's environment. In other words, ACT views cognitive fusion as overly rigid control of behavior by verbal rules (Tarbox et al., 2020; see also Dixon et al., 2020). From an ACT perspective, when a person takes their thoughts literally, it results in insensitivity to direct contingencies of reinforcement by impeding contact with direct antecedents and consequences of behavior (Hayes, Strosahl, \& Wilson, 2012c). As McCracken et al. (2014) put it, cognitive fusion creates difficulties in tracking experiences outside of the actual content of those specific thoughts that exert excessive control over behavior.

What are the implications of cognitive fusion from a health perspective? "Fusion" with illness or disease-related thoughts such as "That medical procedure is just too frightening to even think about" or "It won't make any difference if I do not exercise anyway" is associated with a tendency to act in accordance with such thoughts. Treating thoughts as if they are true can come to exert rigid influence over illness-related behavior (Trindade et al., 2018). For example, fusion with such thoughts could lead to patterns of behavioral avoidance such as not adhering to a medication regime, going to medical checkup appointments, or taking a daily walk in the open air-avoidance strategies that will paradoxically worsen ill health (Trindade \& Ferreira, 2014); thus, engaging in healthier lifestyle behaviors becomes ever more challenging.

It is not just avoidance of potential physical pain that makes cognitive fusion and experiential avoidance a particularly potent combination in undermining physical health and wellbeing (Bardeen \& Fergus, 2016). Fusion with thoughts effectively becomes a rule that is reinforced by the literal context. For example, "it's just a couple of drinks" may help justify regular alcohol consumption but create health complications later in life. Cognitive fusion with such thoughts helps facilitate experiential-avoidance behaviors such as suppressing unpleasant thoughts of liver failure or ignoring warning signs such as yellowing skin, while adhering to the rule "it's just a couple of drinks."

Cognitive defusion is at the opposing end of the spectrum to cognitive fusion. As a procedure (see Assaz et al., 2018; Tarbox et al., 2020), defusion aims to loosen the relationship between thought and action by encouraging clients to see thoughts as verbal stimuli that come and go rather than as verbal stimuli that represent literal truths about external contingencies. From an applied behavior analysis practitioner perspective, defusion techniques aim to reduce the control of overly rigid verbal rules on behavior and facilitate an increase in the range and breadth of one's behavioral repertoire by one responding to such thoughts and rules for what they are: private events (see Tarbox et al., 2020). In a health context, cognitive defusion interventions (e.g., Karekla et al., 2020) can help loosen the rigid functions of verbal stimuli to facilitate an expansion of the person's behavioral repertoire. For example, if a person is fused with the thought "I won't go for a walk if it's cold and damp," that might lead to a restricted repertoire of sedentary behavior during long, dark winter months. With cognitive defusion, the aim is to alter the functional context so that the person sees this thought as just a thought (i.e., verbal stimulus) that does not have to restrict their behavioral repertoire (i.e., rarely leaving the house for exercise in winter months).

\section{Lack of Values Clarification}

Where cognitive fusion and experiential avoidance result in rigid, problematic rule following (e.g., "We're all going to die anyway, so why should I quit drinking/smoking/binge eating?'), it often reflects a lack of contact with a person's values. It might be the case that many people go through life without ever articulating the values by which they would like to live. Contact with values might help counteract some of the rigid control that verbal rules have over a person's lifestyle. For example, if a person notes that "I would like to play a big part in helping and seeing my grandchildren grow up" because they value intergenerational family time, then this could help loosen the control of the verbal rule (i.e., "We're all going to die anyway, so why should I quit ... . ?"). In other words, they become more aware that their verbally constructed rules and rigid behavioral patterns are in conflict with access to valuesbased reinforcers (see Skinner, 1971, for an account of values of reinforcing stimuli), and that if they quit the unhealthy habit, they might live longer and experience their grandchildren for a greater length of time. 
Tarbox et al. (2020) stated that values, from a behavioral conceptualization, can be defined as verbal rules that serve the function of motivating operations that alter (i.e., increase or decrease) the effectiveness of stimuli as reinforcers or punishers. Analyzed in this way, values facilitate overt behavior that evokes such stimuli. From an RFT point of view, values can be defined as sources of positive reinforcement that are overarching (Villatte, 2020). Dixon and Paliliunas (2020) proposed that behavior analysts teach clients to identify personal reinforcers, build verbal descriptions of those reinforcers, discriminate between situations that will provide access to those reinforcers and those that will not, and develop selfmanagement plans to maintain values-consistent behavior.

With respect to values and physical health, behavior analysts need to help clients focus on specific health-related values rather than on identifying broad values per se. Stapleton et al. (2020) examined values in relation to key health-related behaviors - physical activity, quality of diet, quality of sleep, alcohol consumption, and smoking - in a cross-sectional sample of Irish university students. Stapleton et al. found that measures of general values-directedness did not function well as predictors of health behavior. It must be acknowledged that a key limitation is that college samples are particularly prone to delay and probability discounting due to their youth and that potential long-term ill-health effects are far too distant to impact current behavior. However, this finding suggests that the proposed link between the process of values clarification and subsequent health-behavior change (e.g., Dahl, 2015) might not always function as expected, and more research needs to be conducted in this area.

The following section will present an overview of three particular health domains where ACT-based interventions appear to have encouraging signs of efficacy: obesity (including weight management and physical activity), cancer, and chronic pain.

\section{ACT and Obesity}

Lillis et al. (2020) noted that obesity is one of the leading causes of preventable morbidity and mortality worldwide. Two treatment packages derived from ACT principles, referred to as acceptance-based therapy (ABT) and valuesbased healthy living (VHL), seem effective in facilitating and sustaining weight loss (see Lillis et al., 2020). For example, in a 12-week ABT program, participants lost an average of $8.1 \%$ of their initial weight postintervention and maintained these weight losses 6 months later (Forman et al., 2009). Forman et al. (2013) conducted a year-long randomizedcontrolled-trial group ABT intervention with 128 overweight individuals and followed up with participants 6 months posttreatment (i.e., 18 months after initial weight assessment). Forman et al. (2013) reported that ABT participants' average weight loss was favorable compared to a standard behavioral intervention control group. In a later study with 190 overweight individuals (Forman et al., 2016), ABT-group participants lost considerably more weight (13.3\%) than did those receiving standard behavioral treatment $(9.8 \%)$.

In the context of physical activity, Butryn et al. (2011) reported improvements in the quality and intensity of bouts of physical activity among college students following an ABT intervention when compared to a standard educational program. More recently, an ABT protocol was applied to a sample of adults who were trying to maintain clinically important levels of exercise (i.e., moderate- to moderate-to-vigorous intensity; MVPA; Butryn et al., 2018). The ABT intervention resulted in increased time per week engaged in MVPA. This is an important finding, as public health literature repeatedly reports that MVPA provides substantive and varied benefits for overall health and well-being (e.g., Reiner et al., 2013).

$\mathrm{ABT}$ and VHL programs are adaptable and may help reach larger numbers of clients than more typical one-to-one treatment interventions. They are generally applied to groups of between 12 and 16 individuals, with a gradual reduction in the number of contact sessions over time (Lillis et al., 2020). Wallin et al. (2018) conducted a study that focused on the three core ACT targets of values, acceptance and mindfulness, and committed action, using a self-help protocol for obesity (see Lillis et al., 2014). Wallin et al. employed nonconcurrent multiple-baseline designs, and participants were randomly assigned to different baseline lengths according to three staggered intervals. The primary measures of interest were daily ratings of values attainment related to health (e.g., "With regard to your values, to what extent have you taken care of your health today?") and weight-related experiential avoidance (e.g., "To what extent do thoughts and feelings related to your weight keep you from living according to your values?"). Results were somewhat mixed, with significant differences observed in values attainment for seven participants and reductions in experiential avoidance reported for five participants. Little change in physical activity levels was reported.

\section{ACT for Cancer}

Cancer is a complex context for treatment, as it can appear in over 100 different forms, classifications, and varying levels of severity, making a one-size-fits-all approach to intervention untenable (Arch et al., 2020). Furthermore, the psychological needs of people diagnosed with a curable form of cancer are very different from those with a terminal diagnosis. The flexibility of ACT makes it amenable to working with cancer sufferers (e.g., Feros et al., 2013; González-Fernandéz \& Fernández-Rodríguez, 2019; Hawkes et al., 2014; HulbertWilliams et al., 2015). 
A key point to note, however, in the context of adapting ACT for cancer patients is that some strategies or techniques, such as cognitive defusion, might not always be appropriate for a person with cancer. Arch et al. (2020) highlighted one such instance:

People with metastatic cancer often experience distressing thoughts and beliefs ("When I die, my kids won't have a dad") that are true, valid, and devastating to contemplate. We have seen patients with incurable cancer whose parent died of the same disease when the patient was a child, with the patient now repeating this loss for their own children. If a person is haunted by such thoughts, it can be highly invalidating to jump straight into cognitive defusion. (p. 165)

Arch et al. suggested that compassion and acceptance be cultivated as both the client and practitioner sit with such painful private events, acknowledging instances when the negative thoughts and emotions hinder engagement in values-consistent action. This is challenging in practice due to the aversive nature of the verbal networks in which the word "cancer" participates (i.e., many people may assume cancer is equivalent to death), rendering experiential avoidance of such private events more likely and appetitive as a short-term coping strategy. Engaging in valued actions may also be compromised for a person encountering the aversive side effects of cancer treatment.

\section{ACT for Chronic Pain}

ACT for chronic pain is the most widely researched of all health domains within the ACT literature. The effects of ACT appear to compare favorably with standard cognitive behavior treatment packages (e.g., Åkerblom et al., 2020; Hann \& McCracken, 2014; Scott et al., 2016; Vowles et al., 2014; but see Williams et al., 2020, for a challenge to the evidence base of ACT for chronic pain). There is a clear need for approaches that can positively influence the quality of life for a person who suffers from chronic pain.

Dahl et al. (2004) recommended focusing on three core targets of ACT in treating chronic pain: experiential avoidance, cognitive fusion, and lack of values-led behavior. All three processes are interlinked with respect to chronic pain and should be considered in interactive terms. Whereas behavioral avoidance appears adaptive in the context of acute pain (e.g., to avoid compounding an injury), experiential avoidance does not seem so adaptive in the context of ongoing chronic pain. Experiential avoidance might help account for the reluctance of chronic pain sufferers to attempt prescribed exercise plans, for example, or for their avoidance of work tasks or social outings because of the threat of pain. Such avoidance not only increases the risk of developing more debilitating health conditions but also limits the opportunities for reinforcement that a person could contact with a new job, extra money, and wider social networks. Exposure work might be effective in such contexts when clients' avoidance of aversive private events impedes engaging in committed action (Dahl et al., 2004).

A particular challenge in applying ACT with people who suffer from chronic pain is that patients can overly focus on one psychological flexibility process (e.g., valued living) at the expense of others (e.g., cognitive fusion) in order to target a specific pain symptom. This might lead to the increased persistence of other pain-associated problems. Thus, behavioral researchers could conduct empirical studies to identify manipulable contexts that promote the generalization of ACT skills and techniques across the wide array of persistent symptoms that chronic pain sufferers may experience. Furthermore, behavioral practitioners could conduct research on whether ACT-based interventions serve a similar behavioral function across different chronic pain conditions or syndromes, as it appears they might be more or less effective in some contexts than in others. Indeed, behavioral health coaches working within an ACT model could conduct research on identifying novel reinforcers to broaden a client's repertoire of committed actions.

Whereas many of the studies cited in the preceding sections have employed between-subjects group designs, behavioranalytic practitioners look to single-subject methodology for more convincing evidence of treatment efficacy. In a step toward this direction, Barreto and Gaynor (2019) demonstrated the efficacy of 1-hr ACT-based protocol interventions across four case studies, three of which were successful. Each participant received a 60-min protocol that included the following components: a short, focused clinical interview; an introduction to the ACT matrix worksheets; identification of behavioral barriers and internal obstacles; cognitive defusion exercises; physicalizing mindfulness; completion of a values identification exercise; development of an action plan; and competition of a commitment statement. The first successful case study described a 21-year-old female college student who reduced the amount of alcohol consumed to a healthy range recommended by Centers for Disease Control and Prevention guidelines. The second case study featured a 25-year-old college student who was chronically sleep deprived, who increased the number of hours of sleep per night for a higher percentage of time relative to baseline following ACT. The third successful case study focused on a 19-yearold male college student with a poor diet, who showed an increase in self-reported consumption of healthy food items following the ACT intervention. More work in this vein should be conducted using single-subject design methodology to ascertain functional relationships between ACT and behavior change (see Brazeau et al., 2017; Castro et al., 2016; Chancey et al., 2019; Hutchinson et al., 2019). 


\section{ACT for Prevention}

The preceding sections highlighted some health domains where ACT-based interventions seem particularly helpful. However, medical and psychotherapeutic interventions are costly (financially, emotionally, and physically) and are not always available to those who might be most in need. Thus, developing health promotion programs based on behavioranalytic and ACT principles to encourage healthy lifestyle behaviors before health problems develop would be beneficial. Research should focus on the effectiveness and feasibility of ACT for health programs in high schools, colleges, workplaces, and community centers. Behavior analysts must also be cognizant of the limitations of individualized interventions if they do not acknowledge where reinforcers lie culturally. For example, it might be difficult to conduct cognitive defusion and values-clarification-based work with a heavy drinker whose social network involves regular alcohol consumption with a group of friends. Disrupting the social contingencies in this context would be challenging. Similarly, in terms of ready reinforcement for eating quick, easy, unhealthy food, it is difficult to implement healthier eating interventions in contexts where fast-food outlets are readily accessible (Lillis et al., 2020). Thus, although ACT may regulate emotional reactivity to private events and broaden behavioral repertoires (e.g., Gould et al., 2018), a greater awareness of wider cultural contingencies at play in influencing health behaviors and daily choices is warranted.

We have explored how relational responding may give rise to rigid patterns of rule following that interfere with a person's engagement in health-related behaviors. We have summarized the literature to date in support of the application of ACT as a strategy for intervention and prevention. We now explore the potential contributions of contextual behavior science to cultural-level health practices, including behavioral health coaching, health education, and health care delivery. We conclude with a call for scaled-up applications to evaluate strategies for promoting healthier societies.

\section{Behavioral Health Coaching}

Behavioral health coaching has caught the attention of behavior analysts in recent years (i.e., Finn \& Watson, 2017; Normand \& Bober, 2020) and may be the ideal profession in which to incorporate ACT. Health coaches typically work in fitness centers, gyms, and clinics to help clients achieve goals related to their overall health (Normand \& Bober, 2020). Health coaches use several strategies that are consistent with applied behavior analysis, including tracking client progress, teaching self-management skills, and arranging for social reinforcement when goals are met (Finn \& Watson, 2017; Rehfeldt, 2020). Its emphasis on measurement, skill generalization and maintenance, and data-based decision making further aligns health coaching within the professional scope of applied behavior analysis (see Normand \& Bober, 2020).

ACT programs could readily complement the work of health coaches by facilitating values clarification and committed actions in clients working to improve their health outcomes. Health coaches might promote psychological flexibility in their clients if they can identify rigid rule-following and experiential-avoidance behaviors in which clients have been engaging that are incompatible with values-consistent healthrelated behaviors. A health coach could work with a client to identify personal reinforcers with which they have lost contact, build up verbal descriptions of those reinforcers, and teach self-management skills to facilitate contact with those reinforcers (Dixon \& Paliliunas, 2020). In so doing, the client may learn to track experiences outside of the function of their thoughts and expand their behavioral repertoire so that contact with reinforcers for health-related behaviors is established. ACT and mindfulness curricula have already been adopted by those working with youth and professional athletes to improve performance and reduce stress (Biegel \& Corbin, 2018; Saltzman, 2018). For example, Szabo et al. (2019) employed an ACT-based intervention called "Watch Me Try" in comparison to a direct contingency management approach in three young rock-climber athletes with autism spectrum disorder in a concurrent multiple-baseline design. Two of the three climbers with autism spectrum disorder improved their attendance rates and showed increased heart rate, with subsequent enhanced performance observed in athletic competition. The ACT approach is now commonly embraced by life coaches (Blonna, 2010). Thus, a clear pathway to its adoption by health coaches exists, awaiting empirical investigation.

\section{Health Education}

By understanding the processes of transformation of functions and experiential avoidance, behavior analysts are poised to advise the field of health care on its patient-education efforts. Specifically, behavior analysts can offer strategies for how information about chronic health conditions is framed so that, despite unpleasant emotional reactions, behavior change is nonetheless likely to occur. In analyzing the influence of cigarette advertisements on teen smoking, Biglan (2018) found that where and how the behavioral functions of verbal stimuli were actualized in magazine advertisements influenced the likelihood of adolescents engaging in smoking behavior. Similar investigations of the function-altering effects of language could be extended into the study of public health campaigns. For example, rather than using fear tactics to induce behavior change, public health messages could be framed in such a way so as to appeal to people's values, thus serving an 
augmental function. Augmentals, or verbal rules that change the capacity of events to function as reinforcers and punishers, indirectly increase or decrease target behaviors because they increase the value of a given consequence (Zettle \& Hayes, 1982, p. 81). Public health messages might, therefore, carry value-themed messages so as to set the occasion for valuesconsistent behaviors. Rather than advertising the mortality rates of a particular disease, a message might instead focus on the positive health benefits of prevention behavior, such as, for example, "Your cells will thank you for eating freshly grown produce," "Don't you want healthy, natural-looking skin?" and "Imagine how good you will feel and how great you will sleep after exercising." Jackson et al. (2016) explored the augmental functions of health messages in exactly this manner, demonstrating that participants in an indoor cycling class exercised harder when reinforcer-focused signage was visible during their exercise than when it was not. Exploring where such messages are disseminated also seems in order. Posting information in doctors' offices and medical clinics, where they are encountered infrequently and viewed during times of stress, may be less beneficial than a wider circulation on social media, television, and print media that can be viewed during everyday life. In short, altering the context in which public health messages are accessed may better occasion values-consistent behavior. Biglan (2018) suggested that single-systems methodology be "scaled up" so that the effects of such cultural-level manipulations could be evaluated outside of the laboratory.

Researchers in the field of health communication have been exploring the role of humor-based messages in promoting screening, self-exams, and other prevention behaviors. Humor-based messages were found to improve attitudes about breast and testicular exams in undergraduate students relative to fear-inducing messages, and hope-inspiring messages increased participants' intentions to engage in behavior change relative to messages associated with fear (Nabi, 2015, 2016). In addition, Blanc and Brigaud (2014) reported that humorous messages received prolonged attention, were evaluated as being more convincing, and were better retained by participants relative to nonhumorous advertisements. Framing messages with humor may help reduce the literal functions of fearprovoking verbal stimuli, making engagement in behaviors previously avoided more likely. Such a simple, systemslevel change may go a long way toward facilitating the values clarification necessary for a healthier society.

\section{Reconceptualizing Health Care}

Behavior scientists are prepared to contribute to a reconceptualization of health care delivery, work that is already underway in the field of alternative medicine. It is now widely recognized that short- and long-term stress can affect bodily functions in a number of ways: Long-term stress has been linked to high blood pressure, inflammation, and disruption of immune, digestive, cardiovascular, sleep, and reproductive systems (National Institute of Mental Health, 2020). For this reason, a number of medical practices employ specialized clinics to teach stress-reduction strategies such as mindfulness. McCabe and Mackenzie (2009) argued that alternative treatments such as mindfulness warrant widespread adoption as a preventative strategy, with an eye toward reducing the incidence of chronic health conditions requiring expensive treatment. These authors envision widespread inclusion of mindfulness training in health care education, and advise tax incentives or discounts on health insurance products for employers who offer mindfulness programs for their employees. The practice of ACT would fit in well with such initiatives. Research should explore, for example, how mindfulness might supplement contingency management approaches for lifestyle behaviors, at the levels of both individuals and also larger systems such as schools, organizations, and communities.

\section{Scaled-Up Applications}

Biglan et al. (2019) defined "scaling up" as the process of moving from an individually focused intervention to the implementation of the intervention to affect an entire population. Recognition of the relational basis of human behavior offers some hope for a language-based approach to teaching people to consider the future consequences of their behavior in the present. Biglan and Barnes-Holmes (2015) proposed that, despite what the literature on delay discounting suggests, people actually do consider future consequences for their behavior. Planning for college, career, social events, and retirement, for example, all involve consideration of long-term contingencies. A repertoire known as deictic framing involves deriving relations along the dimensions of time and place; in other words, changing perspective between here and there and now and then. "I am paying off debts now, but I will have enough money saved to travel in 10 years" and "Someday I will be elderly too" are examples of deictic framing. Planning for the future also involves causal framing, or behaving as though something that happens in the present causes something to happen in the future. Examples of causal frames include "If I smoke now, my lungs will be unhealthy when I get older" or "If I exercise, my heart will be strong for the future." According to Biglan and Barnes-Holmes (2015), the coordination and comparison between now and then may promote the derivation of rule statements such as these. Protocols that promote deictic framing regarding future health outcomes warrant investigation. In fact, laboratory protocols should be created and evaluated for this very purpose. 
Biglan et al. (2019) advocated for the evaluation of systems-wide ACT interventions to create healthier, happier, and less stressed societies. The long-term effects of stressors on physical health are substantial and often proliferate across the life span and generations (Thoits, 2010). Psychological flexibility can be promoted not only via the implementation of ACT protocols in organizations such as schools, workplaces, health care establishments, and community centers but also through the elimination of community stressors. Fast-paced, competitive cultures that value the success of individuals rather than the well-being of entire communities, Biglan et al. maintained, are likely to promote risky, unhealthy behaviors because rigid rule following dominates over valuesconsistent behavior. For example, working late into the evening and eating fast food may be highly encouraged in a university community because "I may not be promoted if they don't see me here working at night." Limiting time for exercise at conferences may be supported because of the busy conference programs and the notion that "I may miss out on opportunities if I'm not around to socially network." Healthy behaviors may be more likely in nurturing, noncompetitive environments where the success of a community is valued as much as individual gain (Biglan, 2020). In addition, collaboration between behavior scientists and public policy makers is needed. Knowledge of how verbal stimuli affect health behaviors can advise in the adoption of government policies for regulating unhealthy behavioral choices. Biglan (2011) outlined ways in which marketing practices might be altered so that nicotine and alcohol are not easily accessible in at-risk communities.

Teaching people to value the well-being of not only themselves but also others may well play a role in prevention efforts. Health outcomes are best for people who are part of engaged social communities (see Strom \& Egede, 2012). People living in communities where caring for others is appreciated report less stress and greater life satisfaction than others (Grinde et al., 2018). Wilson (2016) highlighted the evolutionary basis of caring for one's community, noting that activities such as hunting and gathering, child-rearing, and defending territory were likely to be more successful if performed cooperatively by a group. That health outcomes are poorer for people who are socially isolated further reinforces the idea that a fast-paced, competitive way of life differs from the way humans are genetically adapted to live (Wilson, 2014). As behavior scientists, we may have much to learn from the behavioral repertoires of people residing in intentional communities, or small, tightly knit communities assembled according to some shared values among their members. The study of health-related behaviors in intentional communities may make possible the sort of scaled-up experimentation that Biglan (2018) called for.

\section{A Postscript: COVID-19}

The COVID-19 pandemic has raised many fundamental questions about how we manage not only societies and health care systems but also the relational networks with which people interact. The conceptualization that we have provided in this article fits well with understanding the sometimes-irrational behaviors in which individuals engage during pandemic times. A pandemic serves as a stark mirror to how societies function and what their individuals value most. Not all countries that reported COVID-19 deaths have been affected equally. It is apparent that the effects of swift and strictly imposed lockdown measures in certain countries had positive effects in reducing infection rates and lowering mortality figures from the virus. The pandemic has also shone a blinding spotlight on inequalities in our societies. Although the challenges of combining working from home and caring for children during lockdown measures are well documented, the highest risk of exposure to the virus was for those in the lowest paid jobs, along with health care professionals who were not given the opportunity to work from the safety of home. For many, there was no safety net of salaried employment, but rather a basic survival need to continue to work.

Patterns of symbolic language appear to be commonly used by certain sections of society to justify beliefs and behavior during the global pandemic. RFT and delay and probability discounting can help elucidate the processes underlying specific responses. For example, in the United States, there has been a marked resistance to the wearing of masks in public spaces by some. The objections are often framed in terms of the "self" (e.g., "My rights . ..," "I don't have the virus, so why should I wear one?") rather than "other" (e.g., these statements could be reframed as "I am wearing this mask to protect others/the elderly/the vulnerable," "I am protecting my community," and "I am wearing this mask to protect our key workers/nurses/doctors/carers/grocery store staff"). It seems apparent that government messages that are focused on the individual are less effective than those focused on coming together as a community.

The influence of immediate reinforcers such as going on vacations or holidays is also striking. A certain percentage of the populations of many countries find it very difficult to move beyond beliefs or verbally constructed rules such that summer is in a relation of coordination with holidays or vacations to which they are "entitled." This discounting of the potential effects of infecting others in the community overrides the desire for immediate reinforcement of taking the vacation or holiday "now." There are many forms of these conditional if-then rules. Some take advantage of the hard work undertaken by societies as a whole during lockdowns, so a minority rides on the back of the sacrifices and efforts of the majority. Instead of framing it as "If I don't go on a vacation now, then my year/summer will be ruined," messages 
could be socially framed as "If you go on vacation now, then your risk of infecting yourself and others when you come home is high" or "If I don't go on holidays now, then I am protecting others in my community, and we will hopefully be able to travel safely later."

Cognitive fusion and experiential-avoidance processes may account for the risky rule-following behaviors engaged in by people who avoid medical treatment during the pandemic. Put simply, a person with heart problems who is aware that their heart rate is becoming more irregular, pains in their left arm are becoming more pronounced, and breathing becoming more labored could ignore these potential warning signs of stroke or heart attack as they might engage in experiential avoidance to suppress those private events. Thus, they might not go to see a doctor or emergency room because they fear they might die from a coronavirus infection picked up at the hospital due to fusion with the thought "Hospitals are full of infection; if I go to a hospital, I will catch the virus and die." The knock-on effects of this are likely to be higher rates of serious ill health among people who could have been treated much sooner under normal circumstances.

Finally, there is a noteworthy increase in the spread of conspiracy beliefs at this time. People who tend to believe that climate change and medical vaccinations are a conspiracy are also more likely to believe that COVID-19 is a conspiracy (Freeman et al., 2020). For example, in a UK sample of 2,501 participants, Freeman et al. (2020) found that $15 \%$ showed a pattern of endorsement of COVID-19 conspiracy beliefs with other conspiracy beliefs such as denial of climate change and the effectiveness of vaccines, whereas $10 \%$ showed a high degree of general endorsement. From an RFT perspective, such people might be cognitively fused, via relational processes such as equivalence/coordination, with such thoughts as "Scientists are wrong and paid to make up these lies" or "All governments/institutions are bad and corrupt." Moreover, they could be engaging in experiential avoidance of thinking about an aversive future where bad things could happen: "I might die from COVID-19" or "Climate change will end human life on earth."

\section{Conclusion}

Chronic health conditions create suffering and compromise the abilities of individuals to live lives characterized by wellness and vitality. Skinner (1987) anticipated the bleak reality that people would one day face events like those of 2020, stating, "That many people have begun to find a recital of these dangers tiresome is perhaps an even greater threat" ( $p$. 1). We have analyzed the role of relational framing and the interrelated processes of rule following and experiential avoidance in health behaviors, and considered ACT as a framework for prevention and intervention. We have proposed scaled-up investigations of psychological flexibility at the cultural level and suggested strategies for making purposeful and conscious engagement in healthy behaviors more likely in more members of a society. Skinner (1987) questioned whether it would be "better to be a better world or no world at all" (p. 14). True, verbal relations cannot be unlearned, but the functional contexts in which relations are bound can be altered. By viewing health through the auspices of contextual behavior science, we have the framework for creating evidence-based interventions for supporting healthier repertoires in individuals and societies.

\section{Declarations}

Conflict of interest None of the authors of this manuscript have conflicts of interest to disclose.

Informed consent No human participants were involved in this manuscript so informed consent was not collected.

\section{References}

Arch, J. J., Fishbein, J. N., \& Kirk, A. (2020). Innovations in ACT for cancer. In M. E. Levin, M. P. Twohig, \& J. Krafft (Eds.), Innovations in acceptance and commitment therapy: Clinical advancements and applications in ACT (pp. 155-169). Context Press/New Harbinger.

Akerblom, S., Perrin, S., Rivano Fischer, M., \& McCracken, L. M. (2020). Treatment outcomes in group-based cognitive behavioral therapy for chronic pain: A examination of PTSD symptoms. European Journal of Pain, 24(4), 807-817. https://doi.org/10. 1002/ejp.1530.

Assaz, D. A., Roche, B., Kanter, J. W., \& Oshiro, C. K. B. (2018). Cognitive defusion in acceptance and commitment therapy: What are the basic processes of change? The Psychological Record, 68(4), 405-418. https://doi.org/10.1007/s40732-017-0254-z.

A-tjak, J. G., Davis, M. I., Morina, N., Powers, M. B., Smits, J. A., \& Emmelkamp, P. M. (2015). A meta-analysis of the efficacy of acceptance and commitment therapy for clinically relevant mental and physical health problems. Psychotherapy and Psychosomatics, 84(1), 30-36. https://doi.org/10.1159/000365764.

Augustson, E. M., \& Dougher, M. J. (1997). The transfer of avoidance evoking function through stimulus equivalence classes. Journal of Behavior Therapy and Experimental Psychiatry, 28(3), 181-191. https://doi.org/10.1016/s0005-7916(97)00008-6.

Bardeen, J. R., \& Fergus, T. A. (2016). The interactive effect of cognitive fusion and experiential avoidance on anxiety, depression, stress and posttraumatic stress symptoms. Journal of Contextual Behavioral Science, 5(1), 1-6. https://doi.org/10.1016/j.jcbs.2016.02.002.

Barreto, M., \& Gaynor, S. T. (2019). A single-session of acceptance and commitment therapy for health-related behavior change: Protocol description and initial case examples. Behavior Analysis: Research and Practice, 19(1), 47-56. https://doi.org/10.1037/bar0000093.

Biegel, G. M., \& Corbin, T. H. (2018). Mindfulness for student athletes: A workbook to help teens reduce stress and enhance performance. New Harbinger Publications.

Biglan, A. (2011). Corporate externalities: A challenge to the further success of prevention science. Prevention Science, 12(1), 1-11. https://doi.org/10.1007/s11121-010-0190-5. 
Biglan, A. (2018). The ultimate goal of prevention and the larger context for translation. Prevention Science, 19(3), 328-336. https://doi.org/ 10.1007/s11121-016-0635-6.

Biglan, A. (2020). Rebooting capitalism: How we can forge a society that works for everyone. Values to Action.

Biglan, A., \& Barnes-Holmes, Y. (2015). Acting in light of the future: How do future-oriented cultural practices evolve and how can we accelerate their evolution? Journal of Contextual Behavioral Science, 4(3), 184-195. https://doi.org/10.1016/j.jcbs.2015.06.002.

Biglan, A. M., Johansson, M., Van Ryzin, M., \& Embry, D. (2019). Scaling up and scaling out: Consilience and the evolution of more nurturing societies, Clinical Psychology Review, 81, 101893. https:// doi.org/10.1016/j.cpr.2020.101893.

Blackledge, J. T., \& Hayes, S. C. (2006). Using acceptance and commitment training in the support of parents of children diagnosed with autism. Child \& Family Behavior Therapy, 28(1), 1-18. https://doi. org/10.1300/j019v28n01_01.

Blanc, N., \& Brigaud, E. (2014). Humor in print health advertisements: Enhanced attention, privileged recognition, and persuasiveness of preventive messages. Health Communication, 29(7), 669-677. https://doi.org/10.1080/10410236.2013.769832.

Blonna, R. (2010). Maximize your coaching effectiveness with acceptance \& commitment therapy (1st ed.). New Harbinger Publications.

Bodenlos, J. S., Hawes, E. S., Burstein, S. M., \& Arroyo, K. M. (2020). Association of cognitive fusion with domains of health. Journal of Contextual Behavioral Science, 18, 9-15. https://doi.org/10.1016/j. jcbs.2020.08.001

Brazeau, K., Rehfeldt, R. A., Mazo, A., Smalley, S., Krus, S., \& Henson, L. (2017). On the efficacy of mindfulness, defusion, and behavioral skills training on job interviewing skills in dually-diagnosed adults with developmental disorders. Journal of Contextual Behavioral Science, 6(2), 145-151. https://doi.org/10.1016/j.jcbs.2017.04.002.

Bricker, J. B., Bush, T., Zbikowski, S. M., Mercer, L. D., \& Heffner, J. L. (2014). Randomized trial of telephone-delivered acceptance and commitment therapy versus cognitive behavioral therapy for smoking cessation: A pilot study. Nicotine \& Tobacco Research, 16(11), 1446-1454. https://doi.org/10.1093/ntr/ntu102.

Bricker, J., Wyzynski, C., Comstock, B., \& Heffner, J. L. (2013). Pilot randomized controlled trial of web-based acceptance and commitment therapy for smoking cessation. Nicotine \& Tobacco Research, 15(10), 1756-1764. https://doi.org/10.1093/ntr/ntt056.

Butryn, M. L., Forman, E., Hoffman, K., Shaw, J., \& Juarascio, A. (2011). A pilot study of acceptance and commitment therapy for promotion of physical activity. Journal of Physical Activity and Health, 8, 516-522.

Butryn, M. L., Kerrigan, S., Arigo, D., Raggio, G., \& Forman, E. M. (2018). Pilot test of an acceptance-based behavioral intervention to promote physical activity during weight loss maintenance. Behavioral Medicine, 44(1), 77-87. https://doi.org/10.1080/ 08964289.2016.1170663.

Castro, M., Rehfeldt, R. A., \& Root, W. B. (2016). On the role of values clarification and committed actions in enhancing the engagement of direct care workers with clients with severe developmental disorders. Journal of Contextual Behavioral Science, 5, 201-207. https:// doi.org/10.1016/j.cbs.2016.09.003.

Chancey, C., Weihl, C., Root, W., Rehfeldt, R. A., Takaguchi, C., \& Pritchard, J. (2019). On the effects of mindfulness with direct-care staff in a human service setting. Journal of Contextual Behavioral Science, 12, 160-169. https://doi.org/10.1016/j.jcbs.2018.07.004.

Centers for Disease Control and Prevention. (2021). About chronic diseases. https://www.cdc.gov/chronicdisease/about/index.htm.

Critchfield, T. S., \& Kollins, S. H. (2001). Temporal discounting: Basic research and the analysis of socially important behavior. Journal of Applied Behavior Analysis, 34, 101-122.

Critchfield, T. S., \& Reed, D. D. (2016). Does hearing about cancer influence stimulus control? An exploratory study of verbal modulation of stimulus generalization. The Analysis of Verbal Behavior, 32(1), 4659. https://doi.org/10.1007/s40616-016-0055-5.

Critchfield, T. S., \& Rehfeldt, R. A. (2019). Engineering emergent learning with nonequivalence relations. In J. O. Cooper, T. E. Heron, \& W. L. Heward (Eds.), Applied behavior analysis (3rd ed., pp. 497526). Merrill Publishing.

Dahl, J. (2015). Valuing in ACT. Current Opinion in Psychology, 2, 43 46. https://doi.org/10.1016/j.copsyc.2015.03.001.

Dahl, J., Wilson, K. G., \& Nilsson, A. (2004). Acceptance and commitment therapy and the treatment of persons at risk for long-term disability resulting from stress and pain symptoms: A preliminary randomized trial. Behavior Therapy, 35(4), 785-801. https://doi. org/10.1016/s0005-7894(04)80020-0.

Dixon, M. R., Hayes, S. C., Stanley, C., Law, S., \& Al-Nasser, T. (2020). Is acceptance and commitment training or therapy (ACT) a method that applied behavior analysts can and should use? The Psychological Record, 70(4), 559-579. https://doi.org/10.1007/ s40732-020-00436-9.

Dixon, M. R., \& Paliliunas, D. (2020). Clinical behavior analysis: Integrating $\mathrm{ACT}$ and $\mathrm{ABA}$. In M. E. Levin, M. P. Twohig, \& J. Krafft (Eds.), Innovations in acceptance and commitment therapy: Clinical advancements and applications in ACT (pp. 16-29). Oakland, CA: Context Press/New Harbinger.

Donovan, R. J., Jalleh, G., \& Jones, S. C. (2003). The word "cancer": Reframing the context to reduce arousal. Australia and New Zealand Journal of Public Health, 27(3), 291-293. https://doi.org/ 10.1111/j.1467-842x.2003.tb00397.x.

Dougher, M. J., Augustson, E. M., Markham, M. R., Greenway, D., \& Wulfert, E. (1994). The transfer of respondent eliciting and extinction functions through stimulus equivalence classes. Journal of the Experimental Analysis of Behavior, 62(3), 331-351. https://doi.org/ 10.1901/jeab.1994.62-331.

Dunn, S. M., Patterson, P. U., Butow, P. N., Smartt, H. H., McCarthy, W. H., \& Tattersall, M. H. (1993). Cancer by another name: A randomized trial of the effects of euphemism and uncertainty in communicating with cancer patients. Journal of Clinical Oncology, 11(5), 989-996. https://doi.org/10.1200/jco.1993.11.5.989.

Dymond, S., Bennett, M., Boyle, S., Roche, B., \& Schlund, M. (2018). Related to anxiety: Arbitrarily applicable relational responding and experimental research on fear and avoidance. Perspectives on Behavior Science, 41(1), 189-213. https://doi.org/10.1007/s40614017-0133-6.

Dymond, S., \& Rehfeldt, R. A. (2000). Understanding complex behavior: The transformation of stimulus functions. The Behavior Analyst, 23(2), 239-254. https://doi.org/10.1007/bf03392013.

Dymond, S., \& Roche, B. (2013). Advances in relational frame theory: Research and application. New Harbinger Press.

Dymond, S., Roche, B., Forsyth, J. P., Whelan, R., \& Rhoden, J. (2007). Transformation of avoidance response functions in accordance with same and opposite relational frames. Journal of the Experimental Analysis of Behavior, 88(2), 249-262. https://doi.org/10.1901/jeab. 2007.22-07.

Dymond, S., Roche, B., Forsyth, J. P., Whelan, R., \& Rhoden, J. (2008). Derived avoidance learning: Transformation of avoidance response functions in accordance with same and opposite relational frames. The Psychological Record, 58(2), 269-286. https://doi.org/10.1007/ bf03395615.

Farrand, P., \& Woodford, J. (2015). Effectiveness of cognitive behavioral self-help for the treatment of depression and anxiety in people with longterm physical health conditions: A systematic review and meta-analysis of randomized controlled trials. Annals of Behavioral Medicine, 49(4), 579-593. https://doi.org/10.1007/s12160-015-9689-0.

Feros, D. L., Lane, L., Ciarrochi, J., \& Blackledge, J. T. (2013). Acceptance and commitment therapy (ACT) for improving the lives of cancer patients: A preliminary study. Psycho-oncology, 22(2), 459-464. https://doi.org/10.1002/pon.2083. 
Finn, H. E., \& Watson, R. A. (2017). The use of health coaching to improve health outcomes: Implications for applied behavior analysis. The Psychological Record, 67(2), 181-187. https://doi.org/10. 1007/s40732-017-0241-4.

Fletcher, L., \& Hayes, S. C. (2005). Relational frame theory, acceptance and commitment therapy, and a functional analytic definition of mindfulness. Journal of Rational-Emotive and Cognitive-Behavior Therapy, 23(4), 315-336. https://doi.org/10.1007/s10942-005$0017-7$.

Forman, E. M., \& Butryn, M. L. (2015). A new look at the science of weight control: How acceptance and commitment strategies can address the challenge of self-regulation. Appetite, 84, 171-180. https://doi.org/10.1016/j.appet.2014.10.004.

Forman, E. M., Butryn, M. L., Hoffman, K. L., \& Herbert, J. D. (2009). An open trial of an acceptance-based behavioral intervention for weight loss. Cognitive \& Behavioral Practice, 16(2), 223-235. https://doi.org/10.1016/j.cbpra.2008.09.005.

Forman, E. M., Butryn, M. L., Juarascio, A. S., Bradley, L. E., Lowe, M. R., Herbert, J. D., \& Shaw, J. A. (2013). The mind your health project: A randomized controlled trial of an innovative behavioral treatment for obesity. Obesity, 21(6), 1119-1126. https://doi.org/10. 1002/oby.20169.

Forman, E., Butryn, M. L., Manasse, S. M., Crosby, R. D., Goldstein, S. P., Wyckoff, E. P., \& Thomas, J. G. (2016). Acceptance-based versus standard behavioral treatment for obesity: Results from the Mind Your Health randomized controlled trial. Obesity, 24(10), 2050 2056. https://doi.org/10.1002/oby.21601.

Forsyth, J. P., \& Eifert, G. H. (1996). The language of feeling and feelings of anxiety: Contributions of the behaviorisms toward understanding the function-altering effects of language. The Psychological Record, 46(4), 607-649. https://doi.org/10.1007/bf03395189.

Freeman, D., Waite, F., Rosebrock, L., Petit, A., Causier, C., East, A., et al. (2020). Coronavirus conspiracy beliefs, mistrust, and compliance with government guidelines in England. Psychological Medicine, 1-13. https://doi.org/10.1017/S033291720001890.

Gloster, A. T., Meyer, A. H., \& Lieb, R. (2017). Psychological flexibility as a malleable public health target: Evidence from a representative sample. Journal of Contextual Behavioral Science, 6(2), 166-171. https://doi.org/10.1016/j.jcbs.2017.02.003.

González-Fernandéz, S., \& Fernández-Rodríguez, C. (2019). Acceptance and commitment therapy in cancer: Review of applications and findings. Behavioral Medicine, 45(3), 255-269. https://doi.org/10. 1080/08964289.2018.1452713.

Gould, E. R., Tarbox, J., \& Coyne, L. (2018). Evaluating the effects of acceptance and commitment training on the overt behavior of parents of children with autism. Journal of Contextual Behavioral Science, 7, 81-88. https://doi.org/10.1016/j.jcbs.2017.06.003.

Green, N., \& Dallery, J. (2019). Evaluating the Effectiveness of Education, Feedback, \& Task Clarification to Increase Workplace Physical Activity. Journal of Organizational Behavior Management, 39, 237-246.

Grinde, B., Nes, R. B., MacDonald, I. F., \& Wilson, D. S. (2018). Quality of life in intentional communities. Social Indicators Research, 137(2), 625-640. https://doi.org/10.1007/s11205-017-1615-3.

Guinther, P. M., \& Dougher, M. J. (2015). The clinical relevance of stimulus equivalence and relational frame theory in influencing the behavior of verbally competent adults. Current Opinion in Psychology, 2, 21-25. https://doi.org/10.1016/j.copsyc.2015.01.015.

Hagger, M., Moyes, S., McAnally, K., \& McKinley, L. E. (2020). Known knowns and known unknowns on behavior change interventions and mechanisms of action. Health Psychology Review, 14(1), 199-212. https://doi.org/10.1080/17437199.2020.1719184.

Hann, K. E. J., \& McCracken, L. M. (2014). A systematic review of randomized controlled trials of acceptance and commitment therapy for adults with chronic pain: Outcome domains, design quality, and efficacy. Journal of Contextual Behavioral Science, 3(4), 217-227. https://doi.org/10.1016/j.jcbs.2014.10.001.

Hawkes, A. L., Pakenham, K. I., Chambers, S. K., Patrao, T. A., \& Courneya, K. S. (2014). Effects of a multiple health behavior change intervention for colorectal cancer survivors on psychosocial outcomes and quality of life: A randomized controlled trial. Annals of Behavioral Medicine, 48(3), 359-370. https://doi.org/10.1007/ s12160-014-9610-2.

Hayes, S. C. (2004). Acceptance and commitment therapy, relational frame theory, and the third wave of behavioral and cognitive therapies. Behavior Therapy, 35(4), 639-655. https://doi.org/10.1016/ s0005-7894(04)80013-3.

Hayes, S. C., Barnes-Holmes, D., \& Roche, B. (Eds.). (2001). Relational frame theory: A post-Skinnerian account of human language and cognition. New York: Plenum Press.

Hayes, S. C., Barnes-Holmes, D., \& Wilson, K. G. (2012). Contextual behavioral science: Creating a science more adequate to the challenge of the human condition. Journal of Contextual Behavioral Science, 1(1-2), 1-16. https://doi.org/10.1016/j.jcbs.2012.09.004.

Hayes, S. C., Bissett, R., Roget, N., Padilla, M., Kohlenberg, B. S., Fisher, G., et al. (2004). The impact of acceptance and commitment training on the stigmatizing attitudes and professional burnout of substance abuse counselors. Behavior Therapy, 35(4), 821-835. https://doi.org/10.1016/s0005-7894(04)80022-4.

Hayes, S. C., Luoma, J. B., Bond, F. W., Masuda, A., \& Lillis, J. (2006). Acceptance and commitment therapy: Model, processes, and outcomes. Behavior Research and Therapy, 44(1), 1-25. https://doi. org/10.1016/j.brat.2005.06.006.

Hayes, S. C., Pistorello, J., \& Levin, M. E. (2012). Acceptance and commitment therapy as a unified model of behavior change. The Counselling Psychologist, 40(7), 976-1002. https://doi.org/10. 1177/0011000012460836.

Hayes, S. C., Sanford, B. T., \& Chin, F. T. (2017). Carrying the baton: Evolution science and a contextual behavioral analysis of language and cognition. Journal of Contextual Behavioral Science, 6(3), 314 328. https://doi.org/10.1016/j.jcbs.2017.01.002.

Hayes, S. C., Strosahl, K. D., \& Wilson, K. G. (2012). Acceptance and commitment therapy: The process and practice of mindful change (2nd ed.). New York, NY: Guilford Press.

Hayes, S. C., Wilson, K. G., Gifford, E. V., Follette, V. M., \& Strosahl, K. (1996). Experiential avoidance and behavioral disorders: A functional diagnostic approach to diagnosis and treatment. Journal of Consulting and Clinical Psychology, 64(4), 1152-1168. https:// doi.org/10.1037/0022-006X.64.6.1152.

Hulbert-Williams, N. J., Storey, L., \& Wilson, K. G. (2015). Psychological interventions for patients with cancer: Psychological flexibility and the potential utility of acceptance and commitment therapy. European Journal of Cancer Care, 24(1), 15-27. https:// doi.org/10.1111/ecc.12223.

Hustyi, K. M., Normand, M. P., Larson, T. A., \& Morley, A. J. (2012). The effect of outdoor activity context on physical activity in preschool children. Journal of Applied Behavior Analysis, 45, 401-405.

Hutchinson, V., Rehfeldt, R. A., Pauly, I. P., \& Root, W. B. (2019). Exploring the efficacy of acceptance and commitment therapy and behavioral skills training to teach interview skills to adults with autism spectrum disorders. Advances in Neurodevelopmental Disorders, 3(4), 450-456. https://doi.org/10.1007/s41252-01900136-8.

Jackson, M. L., Williams, W. L., Hayes, S. C., Humphreys, T., Gauthier, B., \& Westwood, R. (2016). Whatever gets your heart pumping: The impact of implicitly selected reinforcer-focused statements on exercise intensity. Journal of Contextual Behavioral Science, 5(1), 4857. https://doi.org/10.1016/j.jcbs.2015.11.002.

Karademas, E. C., Karekla, M., Flourini, M., Vasilou, V. S., Kasinopoulos, O., \& Papacosta, S. S. (2017). The impact of experiential avoidance on the relationship between illness representations, 
pain catastrophising, and pain interference in chronic pain. Psychology \& Health, 1-16. https://doi.org/10.1080/08870446. 2017.1346193.

Karekla, M., Georgiou, N., Panayiotou, G., Sandoz, E., Kurz, A. S., \& Constantinou, M. (2020). Cognitive restructuring vs. defusion: Impact on craving, healthy and unhealthy food intake. Eating Behaviors, 37, 101385. https://doi.org/10.1016/j.eatbeh.2020. 101385.

Kashdan, T. B., \& Rottenberg, J. (2010). Psychological flexibility as a fundamental aspect of health. Clinical Psychology Review, 30(7), 865-878. https://doi.org/10.1016/j.cpr.2010.03.001.

Levin, M. E., Hayes, S. C., Pistorello, J., \& Seeley, J. R. (2016). Webbased self-help for preventing mental health problems in universities: Comparing acceptance and commitment training to mental health education. Journal of Clinical Psychology, 72(3), 207-225. https://doi.org/10.1002/jclp.22254.

Levin, M. E., MacLane, C., Daflos, S., Pistorello, J., Hayes, S. C., Seeley, J., \& Biglan, A. (2014). Examining psychological inflexibility as a transdiagnostic process across psychological disorders. Journal of Contextual Behavioral Science, 3(3), 155-163. https://doi.org/10. 1016/j.jcbs.2014.06.003.

Levin, M. E., Twohig, M. P., \& Krafft, J. (2020). Introduction: Refining acceptance and commitment therapy to meet the challenges of the human condition. In M. E. Levin, M. P. Twohig, \& J. Krafft (Eds.), Innovations in acceptance and commitment therapy: Clinical advancements and applications in ACT (pp. 1-15). Oakland, CA: Context/New Harbinger.

Lillis, J., Dahl, J., \& Weineland, S. M. (2014). The diet trap: Feed your psychological needs \& end the weight loss struggle using acceptance and commitment therapy. Oakland, CA: New Harbinger Publications.

Lillis, J., Dallal, D. H., \& Kirk, A. (2020). Innovations in applying ACT strategies for obesity and physical activity. In M. E. Levin, M. P. Twohig, \& J. Krafft (Eds.), Innovations in acceptance and commitment therapy: Clinical advancements and applications in ACT (pp. 126-139). Oakland, CA: Context/New Harbinger.

Lillis, J., Hayes, S. C., \& Levin, M. E. (2011). Binge eating and weight control: The role of experiential avoidance. Behavior Modification, 35(3), 252-264. https://doi.org/10.1177/0145445510397178.

Manchón, J., Quiles, M. J., Leon, E. M., \& López-Roig, S. (2020). Acceptance and commitment therapy on physical activity: A systematic review. Journal of Contextual Behavioral Science, 17, 135143. https://doi.org/10.1016/j.jcbs.2020.07.008.

McCabe, R. K., \& Mackenzie, E. R. (2009). The role of mindfulness in healthcare reform: A policy paper. Explore, 5(6), 313-323. https:// doi.org/10.1016/j.explore.2009.10.002.

McCracken, L. M., Barker, E., \& Chilcot, J. (2014). Decentering, rumination, cognitive defusion, and psychological flexibility in people with chronic pain. Journal of Behavioral Medicine, 37(6), 12151225. https://doi.org/10.1007/s10865-014-9570-9.

Moffit, R., \& Mohr, P. (2015). The efficacy of a self-managed acceptance and commitment therapy intervention DVD for physical activity intervention. British Journal of Health Psychology, 20(1), 115129. https://doi.org/10.1111/bjhp.12098.

Nabi, R. L. (2015). Emotional flow in persuasive health messages. Health Communication, 30(2), 114-124. https://doi.org/10.1080/ 10410236.2014 .974129$.

Nabi, R. L. (2016). Laughing in the face of fear (of disease detection): Using humor to promote cancer self-examination behavior. Health Communication, 31(7), 873-883. https://doi.org/10.1080/ 10410236.2014.1000479.

National Institute of Mental Health. (2020). Five things you should know about stress. https://www.nimh.nih.gov/health/publications/stress/ index.shtml
Normand, M. P., \& Bober, J. (2020). Health coaching by behavior analysts in practice: How and why. Behavior Analysis: Research and Practice, 20(2), 108-119. https://doi.org/10.1037/bar0000171.

Normand, M. P., Dallery, J., \& Ong, T. (2015). Applied behavior analysis for health and fitness. Clinical and Organizational Applications of Applied Behavior Analysis, 555-582. https://doi.org/10.1016/B9780-12-420249-8.00022-8.

Rappaport, S. M. (2016). Genetic factors are not the major causes of chronic diseases. PLOS ONE, 11(4), e0154387. https://doi.org/10. 1371/journal.pone.0154387.

Rehfeldt, R. A. (2020). A Review of Devra Davis's (2007) The secret history of the war on cancer: Can the science of behavior contribute to the war on cancer? Behavior and Social Issues, 29(1), 242-254. https://doi.org/10.1007/s42822-020-00027-x.

Reiner, M., Niermann, C., Jekauc, D., \& Woll, A. (2013). Long-term health benefits of physical activity: A systematic review of longitudinal studies. BMC Public Health, 13, 813. https://doi.org/10.1186/ 1471-2458-13-813.

Saltzman, A. (2018). A still quiet place for athletes: Mindfulness skills for achieving peak performance \& finding flow in sports \& life. New Harbinger Publications.

Saphier, N. (2020). Make America healthy again: How bad behavior and big government caused a trillion-dollar crisis. Broadside Books.

Scott, W., Hann, K. E. J., \& McCracken, L. M. (2016). A comprehensive examination of changes in psychological flexibility following acceptance and commitment therapy for chronic pain. Journal of Contemporary Psychotherapy, 46(3), 139-148. https://doi.org/10. 1007/s10879-016-9328-5.

Skinner, B. F. (1971). Beyond freedom and dignity. Knopf/Random House.

Skinner, B. F. (1987). Upon further reflection. Prentice-Hall.

Stapleton, A., O'Connor, M. O., Feerick, E., Kerr, J., \& McHugh, L. (2020). Testing the relationship between health values consistent living and health-related behavior. Journal of Contextual Behavioral Science, 17, 17-22. https://doi.org/10.1016/j.jcbs.2020. 05.002 .

Strom, J. L., \& Egede, L. E. (2012). The impact of social support on outcomes in adult patients with Type 2 diabetes: A systematic review. Current Diabetes Reports, 12(6), 769-781. https://doi.org/10. 1007/s11892-012-0317-0.

Szabo, T. G., Willis, P. B., \& Palinski, C. J. (2019). Watch me try: ACT for improving athletic performance of young adults with ASD. Advances in Neurodevelopmental Disorders, 3(4), 434-449. https://doi.org/10.1007/s41252-019-00129-7.

Tapper, K., Horne, P. J., \& Lowe, C. F. (2003). The Food Dudes to the rescue. The Psychologist, 16(1), 18-21. https://doi.org/10.1007/ s11892-012-0317-0.

Tarbox, J., Szabo, T. G., \& Aclan, M. (2020). Acceptance and commitment training within the scope of practice of applied behavior analysis. Behavior Analysis in Practice. Advance online publication. https://doi.org/10.1007/s40617-020-00466-3

Thoits, P. A. (2010). Stress and health: Major findings and policy implications. Journal of Health and Social Behavior, 51(1 supp), S41S53. https://doi.org/10.1177/0022146510383499.

Trindade, I. A., Barbosa, R., Ferreira, C., \& Pinto-Gouveia, J. (2020). Further validation of the Cognitive Fusion Questionnaire-Chronic Illness (CFQ-CI) in different health condition samples. Journal of Contextual Behavioral Science, 16, 45-48. https://doi.org/10.1016/ j.jcbs.2020.03.004.

Trindade, I. A., \& Ferrreira, C. (2014). The impact of body image-related cognitive fusion on eating psychopathology. Eating Behavior, 15(1), 72-75. https://doi.org/10.1016/j.eatbeh.2013.10.014.

Trindade, I. A., Ferreira, C., \& Pinto-Gouveia, J. (2018). The longitudinal effects of emotion regulation on physical and psychological health: A latent growth analysis exploring the role of cognitive fusion in 
inflammatory bowel disease. British Journal of Health Psychology, 23(1), 171-185. https://doi.org/10.1111/bjhp.12280.

Tyndall, I., Roche, B., \& James, J. E. (2009). The interfering effect of emotional stimulus functions on stimulus equivalence class formation: Implications for the understanding and treatment of anxiety. European Journal of Behavior Analysis, 10(2), 121-140. https://doi. org/10.1080/15021149.2009.11434320.

Upton, D. C., Upton, P., \& Taylor, C. (2013). Increasing children's lunchtime consumption of fruit and vegetables: An evaluation of the Food Dudes programme. Public Health Nutrition, 16(6), 1066-1072. https://doi.org/10.1017/s1368980012004612.

Vilardaga, R., Hayes, S. C., Levin, M. E., \& Muto, T. (2009). Creating a strategy for progress: A contextual behavioral science approach. The Behavior Analyst, 32(1), 105-133. https://doi.org/10.1007/ bf03392178.

Villatte, M. (2020). Using clinical RFT to enhance our ACT interventions: The example of values work. In M. E. Levin, M. P. Twohig, \& $\mathrm{J}$. Krafft (Eds.), Innovations in acceptance and commitment therapy: Clinical advancements and applications in ACT (pp. 30-40). Oakland, CA: Context Press/New Harbinger.

Vowles, K. E., Sowden, G., \& Ashworth, J. (2014). A comprehensive examination of the model underlying acceptance and commitment therapy for chronic pain. Behavior Therapy, 45(3), 390-401. https:// doi.org/10.1016/j.beth.2013.12.009.

Wallin, E., Parling, T., Weineland, S., \& Dahl, J. (2018). Acceptance and commitment therapy to promote value attainment among individuals with overweight: A multiple baseline evaluation. Journal of
Contextual Behavioral Science, 10, 41-49. https://doi.org/10.1016/ j.jcbs.2018.08.007.

Williams AC de, A., Fisher, E., Hearn, L., \& Eccleston, C. (2020). Psychological therapies for the management of chronic pain (excluding headache) in adults. Cochrane Database of Systematic Reviews. https://doi.org/10.1002/14651858.CD007407.pub3.

Wilson, D. S. (2014). Does altruism exist? Culture, genes, and the welfare of others. Yale University Press.

Wilson, D. S. (2016). Quality of life from an evolutionary perspective. Applied Research in Quality of Life, 11(2), 331-342. https://doi.org/ 10.1007/s11482-014-9341-3.

World Health Organization. (2021a). The global burden of chronic disease. http://www.fao.org/3/ac911e/ac911e04.htm.

World Health Organization. (2021b). Diabetes. https://www.who.int/ health-topics/diabetes\#tab=tab_1.

Zettle, R. D., \& Hayes, S. C. (1982). Rule-governed behavior: A potential theoretical framework for cognitive-behavioral therapy. In S. C. Hayes (Ed.), The act in context: The canonical papers of Steven C. Hayes (pp. 7-37) Routledge/Taylor \& Francis Group.

Zhang, C.-Q., Leeming, E., Smith, P., Chung, P.-K., Hagger, M. S., \& Hayes, S. C. (2018). Acceptance and commitment therapy for health behavior change: A contextually-driven approach. Frontiers in Psychology, 8, e2350. https://doi.org/10.3389/fpsyg.2017.02350.

Publisher's Note Springer Nature remains neutral with regard to jurisdictional claims in published maps and institutional affiliations. 